25. Shah A, Suresh S, Thomas R, Smith S. Epidemiology and profile of pediatric burns in a large referral center. Clinical Pediatrics. 2011;5:391-395.

26. Sharma PN, Bang RL, Al-Fadhli AN, Sharma P, Bang S, Ghoneim IE. Paediatric burns in Kuwait: Incidence, causes and mortality. Burns. 2006;32:104-111.

27. Tan KT, Prowse PM, Falder S. Ethnic differences in burn mechanism and severity in a UK paediatric population. Burns. 2012;38:551-5.

28. Tarim A, Nursal TZ, Yildirim S, Noyan T, Moray G, Haberal M. Epidemiology of pediatric burn injuries in Southern Turkey. Journal of Burn Care \& Rehabilitation. 2005;26:327-30.
29. Teo A, Van As AB, Cooper J. A comparison of the epidemiology of paediatric burns in Scotland and South Africa. Burns. 2012;38(6):802-6.

30. World Health Organization. The Global burden of disease 2004 update Geneva, Switzerland: World Health Organization. 2008:157.

31. Xu JH, Qiu J, Zhou JH, Zhang L, Yuan DF, Dai W, Gao L. Pediatric burns in Military Hospitals of China from 2001 to 2007: A Retrospective study. Burns. 2014;40:1780-88

32. Zhou B, Zhou X, Ouyang L, Huang X, Zhang M, ren L, Liang P. An epidemiological analysis of paediatric burns in urban and rural areas in South Central China. Burns. 2014;40:150-6.

\title{
Автори
}

Емилия Каишева, УС по съдебна медицина, Медицински университет, Варна, emiliakaisheva@gmail.com;

Добринка Радойнова, Клиника по Съдебна медицина, УБ „Света Марина” ЕАД, Варна, dradoinova@mail.bg;

Йоланда Заякова, Клиника по термична травма, пластично-възстановителна и естетична хирургия „МБАЛ - Варна”, zayakova@yahoo.com

\section{СРАВНИТЕЛЕН АНАЛИЗ НА НАГЛАСИТЕ НА БИЗНЕС-ОПЕРАТОРИ И ПОТРЕБИТЕЛИ ОТНОСНО ВЪВЕЖДАНЕТО НА ДАНЪК „ВРЕДНИ ХРАНИ“}

\author{
Я. Тошкова, Цв. Търпоманова, Д. Янчев, М. Пенкова
}

\section{COMPARATIVE ANALYSIS OF CONSUMER AND BUSINESS OPERATORS ATTITUDES CONCERNING THE INTRODUCTION OF A "HARMFUL FOODS" TAX \\ Y. Toshkova, Tsv. Tarpomanova, D. Yanchev, M. Penkova}

Рез юме. През последните години се увеличава консумацията на преработените храни и храненето в заведения. Това от своя страна води до повишената употреба на енергийно-калорична храна с високо съдържание на транснаситени мазнини, захари и сол. Според експерти прекомерната консумаиия на продукти, които съдържат тези съставки могат да са предпоставка за развитие на хронични незаразни болести - затльстяване, захарен диабет, сърдечносъдови заболявания и някои видове рак. В тази връзка, в България се представя законопроект за данък за обществено здраве (ДОЗ). Целта на настоящата разработка е да се сравнят позищитте на потребителите и бизнес-операторите на храни и напитки относно въвеждането на данък „вредни храни“. Анкетирани са 320 потребители и 51 бизнес-оператори на храни и напитки. Наблюдава се съществена разлика в изразеното мнение на бизнес-операторите и потребителите относно въвеждането на ДОЗ. Над половината от анкетираните потребители (56,5\%) одобряват облагането на храни с т.н. ,вредни съставки“", а в същото време над половината от произведителите $(56,8 \%)$ не одобряват въвеждането на такъв вид данък. Има страни членки на ЕС, в които въведените налози върху храните са отменени поради несъстоятелност на прилагания норматив. По-иелесъобразно би било в нашата страна да се регламентират норми за количествено съдържание на определени съставки (захар, сол, трансмастни киселини, кофеин).

$\boldsymbol{S}$ u $\boldsymbol{m} \mathbf{m}$ a ry. Increased consumption of processed foods leads to an increased use of energy-rich food with a high content of hydrogenated fats, sugars and salt, which is a prerequisite for the development of some socially significant chronic diseases. In this regard, a bill for public health tax (PHT) has been drafted in Bulgaria. The purpose of this paper is to compare the position of consumers and food and beverage business operators on the introduction of the "harmful food" tax. More than half of the respondents $(56.5 \%)$ approve, while $56.8 \%$ of the producers oppose the introduction of such a tax. The majority of the two groups believe that taxation will lead to an increase in the price of the products concerned. According to $58.4 \%$ of consumers, the tax will limit the production of foods containing harmful ingredients. This opinion is maintained by only $15.6 \%$ of the producers. A change in food choices after introducing appropriate marking would be made by $70 \%$ of consumers, but more than half of the business operators have doubts about this choice. Therefore, it would be most appropriate for our country to define norms of the quantitative content of hydrogenated fats, sugars and salt.

Key words: public health tax, "harmful food" tax, consumer, business operator, harmful ingredients (sugar, salt, hydrogenated fats)

\section{Въведение}

С въвеждането на новите технологии при производство на храни и напитки, модернизацията и бързата урбанизация, се променят моделите на хранене не само в развитите, но и в развиващите се страни. Увеличава се консумацията на преработените храни и храненето в заведения. Това, от своя страна, води до повишената употреба на енергийно-калорична храна с високо съдържание на наситени мазнини, трансмаз- нини, захари и сол. [11] Тези съставки подпомагат процесите на производство на храни и напитки, но прекомерната употреба на продукти, които ги съдържат, е предпоставка за развитие на хронични незаразни болести - затльстяване, захарен диабет, сърдечносъдови заболявания и някои видове рак. Затова, по препорька на Световната здравна организация, политиката на Европейския съюз е насочена към ограничаване на консумацията на продукти с високо съдържание на захар, 
сол и транснаситени мазни киселини (ТМК). [10, 14, 15] България, като страна членка на ЕС, също разработва програми в областта на профилактиката и промоцията на здраве. Представеният през 2015 г. проектозакон за данък за обществено здраве (ДОЗ), известен сред обществото като данък „вредни храни“, също е част от превантивните мерки на държавата. [1] Този закон предвижда облагането с данък на определени групи храни - тестени сладкарски, захарни изделия, чипсове, ядки, напитки със захар, подсладители, енергийни и алкохолни напитки. $[1,6]$ Част от тежестта на данъка ще се поеме от потребителите, като в крайна сметка нездравословните храни ще станат по-скъпи от здравословните, а това вероятно ще стимулира създаването на по-здравословен хранителен режим сред населението. $[8,12]$

Подобни данъци и такси са въведени преди години и в други държави - Белгия, Дания, Финландия, Франция, Унгария, Ирландия [4, 9], но налагането им в различните страни не е хармонизирано. В някои страни въведеният данък след определен период от време е отменен или видоизменен поради неефективност [8]. Асоциацията на производителите на безалкохолни напитки в България изказва мнение, че „,....няма сериозно изследване в света, което да показва, че подобен данък води до намаляване на заболяванията и на проиента от хората с наднормено тегло и затльстяване. “ [7] Експерти в областта на храненето и диетиката също смятат, че облагането на храни с данък е неефективна мярка за превенция на заболяванията. Обикновено хроничните болести са с мултифакторна генеза и освен режима на хранене значение имат генетичната предразположеност, начинът на живот, двигателната култура и др. [5]

Целта на настоящата разработка е да се установят и сравнят позициите на потребителите и бизнес-операторите на храни и напитки относно въвеждането на данък „вредни храни“" и чрез отчитането на тези нагласи да се анализира потенциалният ефект от въвеждането на този данък в България.

\section{Материали и методи}

Чрез пряка анонимна анкета са изследвани 320 потребители и 51 бизнес-оператори на храни и напитки. Въпросите от анкетата са насочени към конкретни оценки и очаквания на респондентите при въвеждане на данък „Обществено здраве“. Изследването е проведено в периода майюни 2017 г. Резултатите са обработени чрез математикостатистически методи и графичен анализ.

\section{Резултати и обсъжАане}

Обикновено въвеждането на данък е съпроводено със съпротива от страна на обществото. Малко над половината от анкетираните потребители (56.5\%) одобряват налагането на такси върху храните. Очаквано, по-малка част от бизнесоператорите (43.2\%), изказват одобрение, т.е. съотношението „за“" и ,против““ от двете групи е обратно пропорционално. Фигура 1. Одобрение на респондентите относно въвеждането на ДОЗ

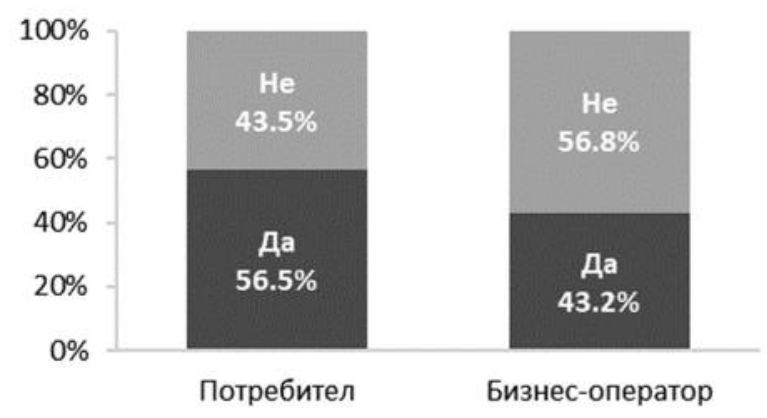

Голям е дельт на анкетираните, които са убедени, че с въвеждането на данък върху храните ще се повиши цената на облагания продукт. Изказването се подкрепя от $88.7 \%$ от потребителите и $70.5 \%$ от бизнес-операторите. В действителност повишаване на цената на продуктите с данък ще е наложителна, защото по представения законопроект данъчната ставка ще се увеличава пропорционално на вложените съставки (ТМК, захар и сол) в храните. [3] Очаква се крайната тежест на въведените такси да е за сметка на клиента.

Значима е разликата в мнението относно поскъпването на всички продукти след въвеждане на данъка. Повече от половината потребители (53\%) и почти всеки пети производител (19.6\%) застъпват становището, че такова поскъпване ще има.

Готови да ограничат производството на облагани с данък храни са $15.6 \%$ от бизнес-операторите, а такова действие от фирмите очакват над половината (58.4\%) от потребителите.

Интересно е, че 70.3\% от консуматорите са уверени, че след въвеждане на данъка, ще се увеличат изкуствените заместители в продуктите. Изкуствените заместители са вид технологични добавки, които заменят естествените съставки по отношение на овкусителите и подсладителите. Такива са Ацесулфам К - Е 950, Аспартам - Е 951, Цикламат - Е 952, Захарин - Е 954, за които също ще се определят такси само при употребата им в плодови сокове и подсладени води. [2, 13]

Твърдението, че масово ще се използват заместители, се подкрепя от всеки десети производител $(9.8 \%)$. Значимото различие в мненията говори за съмнението на потребителите, че производителите ще спазват коректно установените норми.

В обобщение, мнението на потребителите и бизнесоператорите относно влиянието на данъка върху цената и качеството на продуктите се различава значително. (Фигура 2)

Фигура 2. Разпределение на мнението на потребители и бизнес-оператори с отговор „Да“ относно влиянието на данъка върху облагания продукт и другите храни

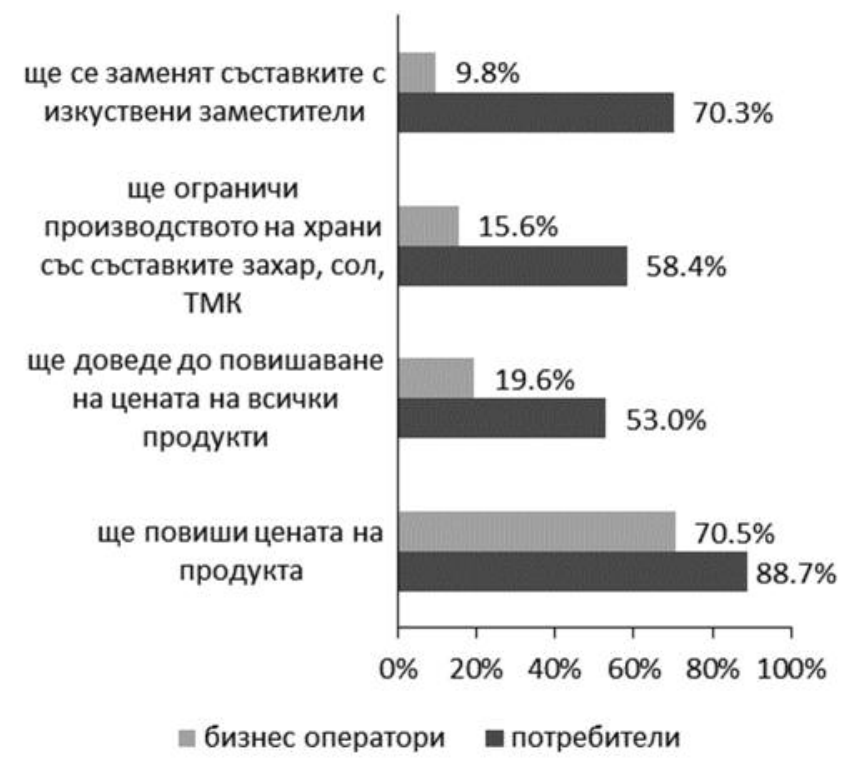

Експертите смятат, че въвеждането на маркировка (знак) върху етикетите на продуктите под формата на т.нар. „светофар“", със зелен, жълт или червен кръг в зависимост от вложеното количество на вредните съставки, ще доведе до информиран избор на храна. Друг ефект би бил намаляването 
на консумацията на продукти с високо съдържание на този вид съставки, което ще принуди производителите да пренасочат производството си към здравословни храни. Тези мотиви се подкрепят от болшинството от консуматорите (70\%), според които специфичната маркировка би довела до промяна в избора на храна. Обратното - над половината (56.8\%) от бизнес-операторите не споделят идеята. (Фигура 3)

Фигура 3. Разпределение на мнението на производителите и бизнес-операторите относно промяна в избора на храна на потребителите след въвеждането на маркировка (червен кръг) върху етикетите на продукти с високо съдържание на захар, сол и транс-наситени мазнини

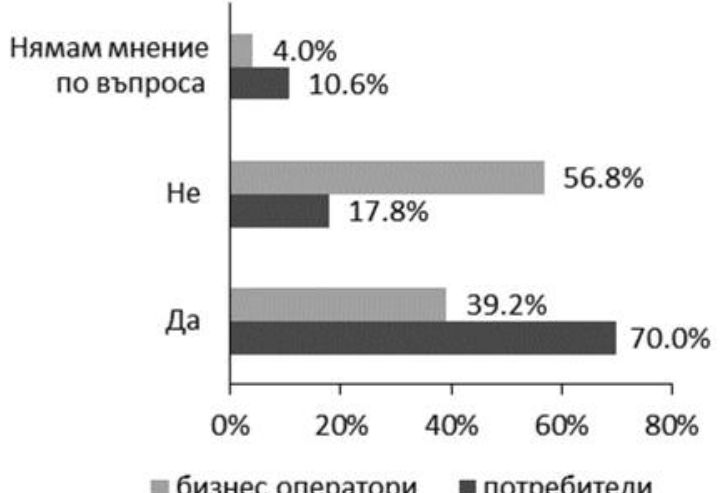

\section{Закмючение}

Нагласите по отношение на въвеждане на ДОЗ, а впоследствие и поведението на потребители и бизнес оператори, са предиктори на ефективността на предлаганата промяна в нормативната уредба в страната. И двете групи респонденти смятат, че данъкът ще доведе до повишаване на цените на облаганите продукти. Очакванията на купувачите за ограничаване на производството на храни с „вредни съставки“ се споделят от много мальк дял от фирмите (15.6\%). От друга страна, поставянето на маркировка върху етикетите на продуктите, която да обозначава завишеното съдържание на захар, сол и ТМК, би довело до промяна в избора на храна за $70 \%$ от потребителите, без да е необходимо облагането с данък.

Резултатите показват, че въвеждането на ДОЗ вероятно няма да доведе до желания ефект - ограничаване на производството на храни с вредни съставки. Затова, по-целесъ- образно би било да се регламентират норми за количествено съдържание на определени съставки (захар, сол, трансмастни киселини, кофеин), да не се допуска рекламата на храни, които могат да се определят като „вредни“ и да се осигурят достыпни цени на т.нар. ,полезни храни“ - био храни, плодове, зеленчуци, продукти, произведени по БДС и др.

\section{Библиография}

1. Закон за данък за общественото здраве - проект, октомври 2015 www.mh.government.bg/media/.../proekt-na_zakon-danuk-obshstvenozdrave.docx

2. Кьоле К., „Е-номера и консерванти. Какво поглъщаме с храната“. изд. „Софт-Прес“ 2007 г., стр.1,6,22-29

3. М3, Мотиви към проекта на Закон за данък за общественото здраве, октомври, 2015 г. www.mh.government.bg/.../motivi-proekt-na_zakondanuk-obshstveno-zdrave.docx)

4. Петрова, Ст., „Становище относно предложението за данък върху „вредните храни”, стр. 1, 2, 3,6,13-15, http://ncphp.government.bg/ files/Prof Petrova-Danak nazdravoslovni hrani.pdf

5. Попов, Б., Данъците върху храните не могат да намалят наднорменото тегло, 2015, http://www.desant.net/show-news/34489/ (14.06.2017))

6. Регламент (ЕИО) № 2658/87 на Съвета относно тарифната и статистическата номенклатура и Общата митническа тарифа. Приложение I

7. Становище на Хранително-вкусовата индустрия относно проектозакона за данък „обществено здраве“, октомври 2015, стр. 2, 8, http://www.bsda-bg.org/uploads//documents/FBO PP Food Tax\&Supportive_statments.pdf

8. Caroline Franck, MSc, Sonia M. Grandi , MSc, and Mark J. Eisenberg, MD, American Public Health Association, Taxing Junk Food to Counter Obesity, Am J Public Health . 2013 November; ncbi.nlm.nih.gov, https://www.ncbi.nlm.nih.gov/pmc/articles/PMC3828689/ (08.06.2017)

9. Cornelsen, L., Carreido, A., 2015, Health-related taxes on food and beverages, May 2015. Food Research Collaboration Policy Brief, стр.1, http://foodresearch.org.uk/wp-content/uploads/2015/05/Food-and-beverages-taxesfinal-20-May-2015.pdf, (08.06.2017)

10. European Commission, Survey on Members States' Implementation of the EU Salt Reduction Framework, стр.2, http://ec.europa.eu/health//sites/ health/files/nutrition_physical_activity/docs/salt_report1_en.pdf

11. http://www.who.int/mediacentre/factsheets/fs393/en/

12. Passero Giuliana, Tassare il cibo spazzatura - Giustizia Tributaria, Gennaio 2017,http://www.giustizia-tributaria.it/legalita-fiscale/item/download/2915 940170ec67a59766eae0a49c322376ac

13. Soffritti Morando, Fiorella Belpoggi , Eva Tibaldi at "Life-Span Exposure to Low Doses of Aspartame Beginning during Prenatal Life Increases Cancer Effects in Rats", Jun 2007, <https://www.ncbi.nlm.nih.gov/pmc/articles/PMC1964906/>)

14. WHO, Fiscal Policies for Diet and Prevention of Noncommunicable Diseases Technical Meeting Report, May 2015, Geneva, Switzerland, http://apps.who.int/iris/bitstream/10665/250131/1/9789241511247eng.pdf?ua $==114$

15. WHO/FAO, Diet, nutrition and the prevention of chronic diseases, Geneva 2003, http://apps.who.int/iris/bitstream/10665/42665/1/WHO TRS 916.pdf?ua=1

\footnotetext{
Автори

Яна Тошкова, Цветелина Търпоманова - УС „Инспектор по обществено здраве“, Медицински колеж, МУ - Варна

Димитър Янчев, Маринела Пенкова - УС „Инспектор по обществено здраве“, Медицински колеж, МУ - Варна-студенти
}

\section{Още за д-р Стамен Григоров}

Писмо на професор Масол, известен в света бактериолог по това време от Медицинския факултет в Женева до професор Иля Мечников, оглавяващ Пастьоровия институт в Париж:

„Скъпи приятелю, Моят асистент Стамен Григоров, славянин от България, ме изненада с голямата си упоритост в научноизследователската си работа. Това е един рядък човек и, струва ми се, че на теб, именно на теб, той би могъл да бъде много полезен. След многобройни и последователни опити в моята лаборатория той успя да открие и изолира причинителя на българското кисело мляко. При това подквасата му бе донесена направо от България. Ти работиш, вдъхновяван от стремежа да намериш средство, с което да се продължи човешкият живот. След твоите забележителни „фагоцити“, помисли за българското кисело мляко и за този „пръчковиден бацил“, който откри Григоров и който аз лично видях под микроскопа. Може би той ще ти бъде полезен.“"

Впоследствие професор Иля Мечников кани българина в Пастьоровия институт в Париж, където да изнесе доклад за откритието си пред научния състав на Института.

$C M$ 